\title{
Using an Online Remote Laboratory for Electrical Experiments in Upper Secondary Education.
}

\author{
http://dx.doi.org/10.3991/ijoe.v8iS2.1941 \\ L. Claesson and L. Håkansson \\ Blekinge Institute of Technology, Karlskrona, Sweden
}

\begin{abstract}
The use of remote laboratories in courses at university level has been reported in literature numerous times since the mid 90's. In this article focus is on activities carried out by teachers and students, at the Upper Secondary School Level, using the remote laboratory VISIR (Virtual Instrument Systems in Reality). The Upper Secondary School, Katedralskolan in Lund, Sweden, cooperate with Blekinge Institute of Technology, Sweden, in a project that concerns the introduction of remote laboratory environment suitable for Upper Secondary School science courses. A remote laboratory in electronics has been introduced and is used as a complement to the traditional workbench in the hands-on laboratory. Significant results from the project are; 1 ) the great interest shown by the students for the remote experiments, 2) the students appreciation for the fact that it was not simulations but actual real experiments, 3) the remote laboratory is easy to implement for use by both teachers and students and 4) it can be used simultaneously by many students.
\end{abstract}

Index Terms-e-learning, experimental work, learning assessment, remote laboratories

\section{INTRODUCTION}

In January 2009 started a project at the upper secondary school, Katedralskolan Lund, Sweden, together with Blekinge Institute of Technology (BTH), Sweden. The purpose of the project is to develop and to introduce a remote laboratory, suitable for science courses in upper secondary school, based on the online remote laboratory workbench, VISIR laboratory, created at the BTH. The VISIR laboratory is a remote laboratory (RL) created in a project called VISIR (Virtual Instrument Systems in Reality). VISIR aims at forming a group of cooperating universities and other organizations, a VISIR Consortium, creating software modules using open source technologies for online remote laboratories and/or setting up online remote laboratories. At present, the department of Electrical Engineering, BTH, has four different remote laboratories, in different areas, such as antenna theory, electronics, security and vibration analysis. It is the RL dedicated to experiments on electrical and electronic circuits that is currently used in the project between Katedralskolan and BTH. Its architecture and characteristics are well described in several books and articles [1-5]. Apart from $\mathrm{BTH}$, five universities in Europe have set up VISIR online laboratories for electrical experiments, 1) University of Deusto, Bilbao, Spain, 2) The National University of Distance Education, Madrid, Spain, 3) Carinthia Univer- sity of Applied Sciences, Austria, 4) FH Campus WIEN, Wien, Austria and 5) Instituto Politécnico do Porto, Portugal [6-8]. The Indian Institute of Technology Madras in India will set up one soon. A VISIR community has also been established.

VISIR is a client-server architecture, where measurements are carried out on a server and the instrument front panels are displayed on the client computer screen [5]. A significant difference for a remote student compared with a student in a hands-on laboratory is how to wire circuits and how to connect instruments. A remote student uses a suitable telemanipulator instead of a solderless breadboard to perform such actions [3]. VISIR specifies a relay switching matrix and a virtual breadboard combination [3]. The remote student wires the circuit and connects instruments on the virtual breadboard displayed on the computer screen. The physical circuit and the instrument connections are created in the matrix by controlling relays to setup appropriate electrical connections. Only Internet access and a web browser with a Flash player are required to access the remote experimental resources [5]. The client software is automatically downloaded from a web server.

The client software is written using Adobe Flash. It is responsible for displaying and handling the instrument front panels, so the student can set up their experiment and view the measured response. Each front panel is based on a real-life instrument and should look and behave identical, as far as possible, as the actual instrument. Position 2 in fig. 1 illustrates what is displayed on the client's computer display when the DC Power is turned on, which contains an interactive image of the DC Voltage level.

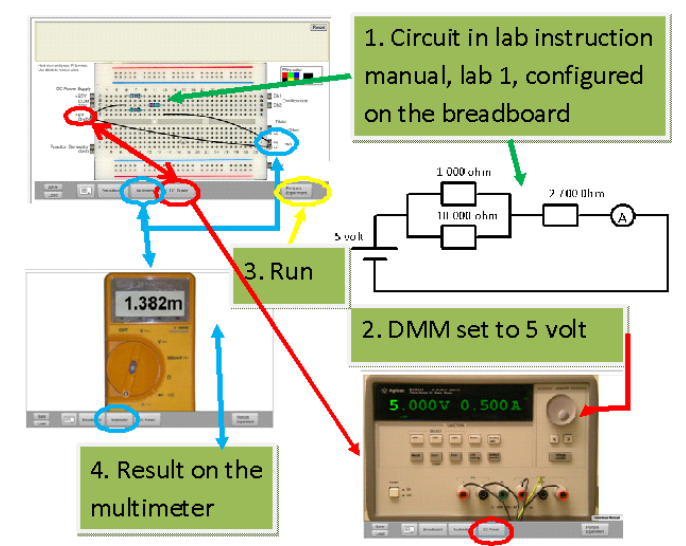

Figure 1. Practical session using VISIR with four steps. Position 2 shows what is displayed on the client's computer display when when the DC Power is turned on. 
Users are then able to interact with these instrument images, which includes animated controls and displays, in the same way as they would when physically operating the instruments in the hands-on laboratory. Basically, the mouse pointer is used to click on buttons or rotate knobs similar to the usage of fingers in the hands-on laboratory to press buttons or turn knobs. The GUI presents the instruments with a sense of realism and functionality that matches the physical instruments. Front panels are interchangeable, so if another model of an instrument is needed; it is possible to select another.

When a measurement is carried out, all the settings of the instruments in the client computer are encoded in a measurement request and sent to the server. The server responsible for carrying out measurement is called a measurement server. It is software written in $\mathrm{C}++$ and has the responsibility to validate the settings and the circuit sent by the client. The server also needs to figure out if the circuit wired on the virtual breadboard can safely be implemented by the switching matrix. When everything is verified and safe, the measurement is carried out and the results are sent back to the client. The client can then display the results on the instruments front panels. [5]

In a typical classroom for physics at Katedralskolan there are ten workbenches allowing a number of students to perform experiments simultaneously supervised by one teacher. Also, in all science-classrooms it is possible to have hands-on laboratory work. These classrooms are all equipped with a SMART Board i.e. an interactive, electronic whiteboard which can enhance instruction and learning and a camera connected to TV that can enlarge components and screens of instruments. Why introducing RL when the school has fully equipped scienceclassrooms? The concept of a remote laboratory provides basically new possibilities for students to do laboratory work and become experimenters. Adding a remote operation option to traditional hands on laboratories make them more accessible for students, regardless of whether they are at school or at home. Remote laboratories in electronics are not replacements for hands on labs; they provide a complement to the traditional workbenches. Remote laboratories are open 24/7, and the students can carry out laboratory assignments without any risks of damaging any equipment.

Many virtual laboratories have been developed to help students gain understanding of new concepts by simulating physical systems. Although simulation is a useful and convenient teaching tool it is a poor replacement for real experimental work. Physical experiments provide a great way for students to learn more about nature and its possibilities as well as limitations. The advantages of these RL and comparative studies between: hands-on, simulated, and remote laboratories have been analyzed many times. [9-11]

The continuation of this article is organized as follows: Section II describes the activities carried out by teachers and students at Katedralskolan in Lund using the remote laboratory VISIR, located at BTH, with the emphasis on teaching methods. In our study during 2009-2011 two teachers and 94 students at Katedralskolan were participating in the project between Katedralskolan and BTH. In section III examples of students remote laboratory work is be presented. Section IV report the result of the questionnaire passed to the students, to acquire their opinion about the VISIR lab. Finally section V concludes the paper.

\section{TEACHING METHODS WITH REMOTE LABORATORY}

\section{A. Upper Secondary school system in Sweden.}

Upper secondary schools, in Sweden, are divided into 17 different national programmes with centrally defined programmes curricula that have between two and four centrally defined orientations. The programmes are divided into two general categories, preparatory and vocational programmes. All programmes provide basic qualification's to attend university, while the preparatory programmes typically satisfy a broader range of different special qualifications that may be required to attend some university courses and programmes.

The students at Katedralskolan are distributed amongst three different programmes of study according to [12]:

\section{3-year National Programmes; \\ - Natural Programme \\ - Social Sciences Programme \\ 3-year International Programme; \\ - International Baccalaureate.}

The courses that the students attend depend on programme and orientation. The students at the science programme, a preparatory programme, study two courses in Physics, Physics A and Physics B. These two courses add up to ten percent of the Natural Sciences Programme courses.

The 1st, 2nd and 3rd semesters the students study mechanics, thermal physics, optics, electric currents and potential difference in the physics A course. For the duration of approximately seven weeks they study electrical and electronic circuits in this course. Reminding time, the 4th, 5th and 6th semesters, they attend the course Physics B. The content of the latter course is electric and magnetic fields, electromagnetic induction, alternating current, oscillations and waves, wave phenomena, atomic and nuclear physics, momentum, motion in circles, two dimensional motions. Eight weeks of the semesters of the Physic B course concerns electric fields and alternating current in electrical circuits with components like resistors, capacitors and coils.

Physics A and B have weekly classes of 3 hrs and the teacher decides when to have laboratory work, problem solving or theoretical classes. Students are assessed by two evaluation components: by their lab work performance and by approximately five theoretical examinations during the course. Four grades in the examination are currently used in upper secondary school: Did Not Pass (Icke Godkänd (IG)), Pass (Godkänd (G)), Pass with distinction (Väl Godkänd (VG)) and Pass with special distinction (Mycket Väl Godkänd (MVG)). One and the same teacher usually give both courses, physic A and B, in a class with a size of approx. twenty students.

\section{B. The Learning Management system and Portals of Katedralskolan.}

Fig. 2 illustrates the four main components used at Katedralskolan;

1) INTRANET; to store and manage internal data, 2) PORTAL; to store and manage external data, 3) LMS, the Learning Management System, itslearning, with pedagogic contents, and 4) VISIR, the remote laboratory used 


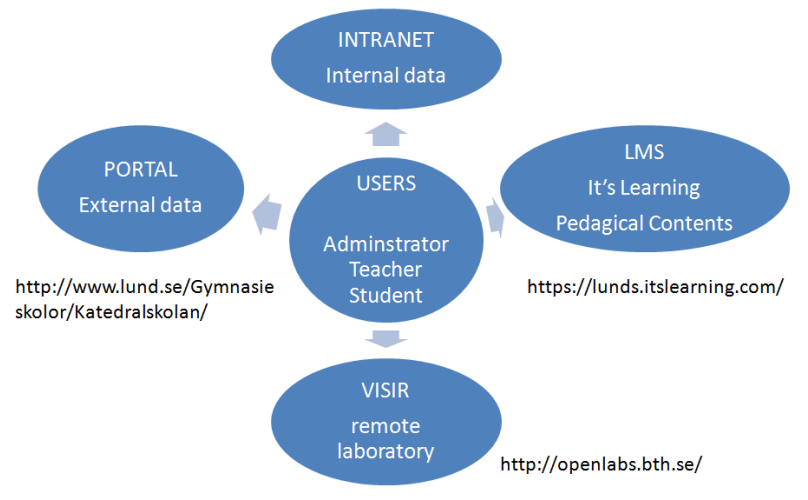

Figure 2. Sites used for institutional and teaching and learning purposes at Katedralskolan in Lund

for experiments on electrical and electronic circuits, located at BTH. All these components have an administrator that may not be the same for all of them.

When starting a new semester, the teachers have access to structured information on the intranet of Katedralskolan and the LMS itslearning, i.e. they will have access to the courses they will be lecturing. All the students enrolled in those courses will have access to teaching \& learning materials made available by their teacher. The intranet of Katedralskolan is only accessible within the school area.

To access the intranet and itslearning the teacher have the same user identity but with different password. The portal for external data is on the internet and is a public website. Here the physics institute of Katedralskolan can be accessed at http://www.katte.se/fysik/. How to manage the access to VISIR laboratory will be described in next paragraph.

\section{The VISIR laboratory}

There are three different levels of access to the VISIR laboratory: 1) administrator, 2) teacher, and 3) student. The administrator is responsible for the general management of the system and he/she is creating courses and deciding the limitations of the recourses for a course. The system is built with a hierarchy; the administrator is overruling both the teacher's and the student's settings. As a teacher you are responsible for a course and handle all administrative tasks concerning the course such as registering students. [5]

To start a course in VISIR requested by a teacher, the Administrator starts by creating the course in VISIR and subsequently adds the responsible teacher for the course. As a support for teaches using the VISIR laboratory there is a comprehensive teacher manual available [13]. The teacher then adds his/her students into this course, see fig 3. This action simply implies copying \& pasting the list of e-mails of the students enrolled in the teacher's course from itslearning into the VISIR laboratory. The student then uses this e-mail to activate his /her account on VISIR. In the list of users, the column encircled in fig. 3, the teacher can see if a student has activated his/her account. Next step for the teacher is to create and add new prepared experiments for students according to the course, see fig. 4. Here the teacher needs to be aware of the components physically available in the matrix, see fig. 5 [14]. The switching matrix is a USB controlled circuit wiring robot, where the student's requested circuit can be realized and measured on. It is built as a stack of cards (PCBs), with a shared bus that passes through them all. Components are connected through relays on what is called component cards, instruments on instrument cards and by controlling the matrix to close relevant relays the circuit can be constructed and the instruments connected. New cards may e.g. be added to the stack, when e.g. more flexibility or new component types are needed.

Available components are;

- resistances from 50 to $220000 \mathrm{ohm}$

- two potentiometers, 10000 and 100000 ohm

- capacitors from 6.8 nanofarad to 10 microfarad

- one coil, 82 millihenry

- diodes

- operational amplifiers

Available instruments are;

- multi-meter

- oscilloscope

- power supply

- function generator

To add a prepared experiment i.e. a set of components and instruments, click "Add prepared experiment" in the course view, see fig. 3. You must first start the client in teacher mode by clicking the link, "name of the course", below the headline "teacher". In this mode, it is possible to select instruments displayed on the instrument shelf and components from the Component Library, which contains a photo and a description of every component defined for the VISIR platform. However, the component Library

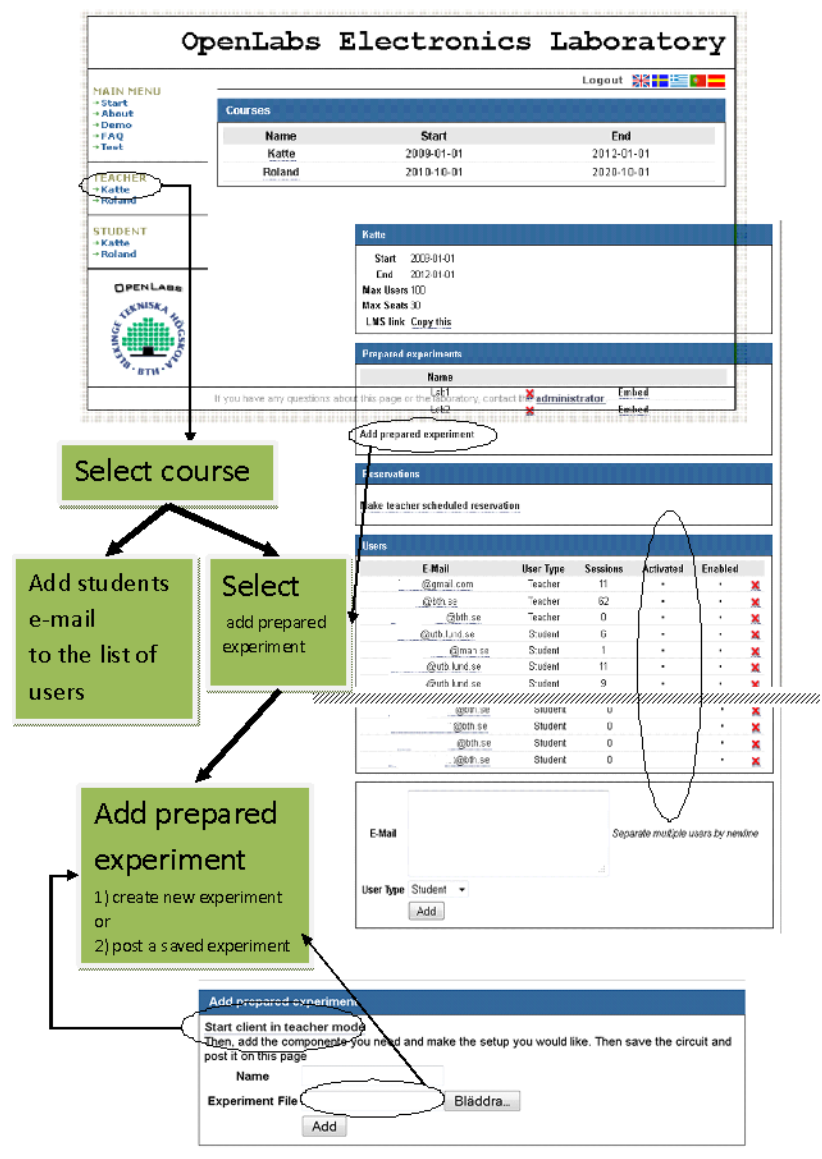

Figure 3. How to add a list of users to a particular course in VISIR to prepared experiments. 


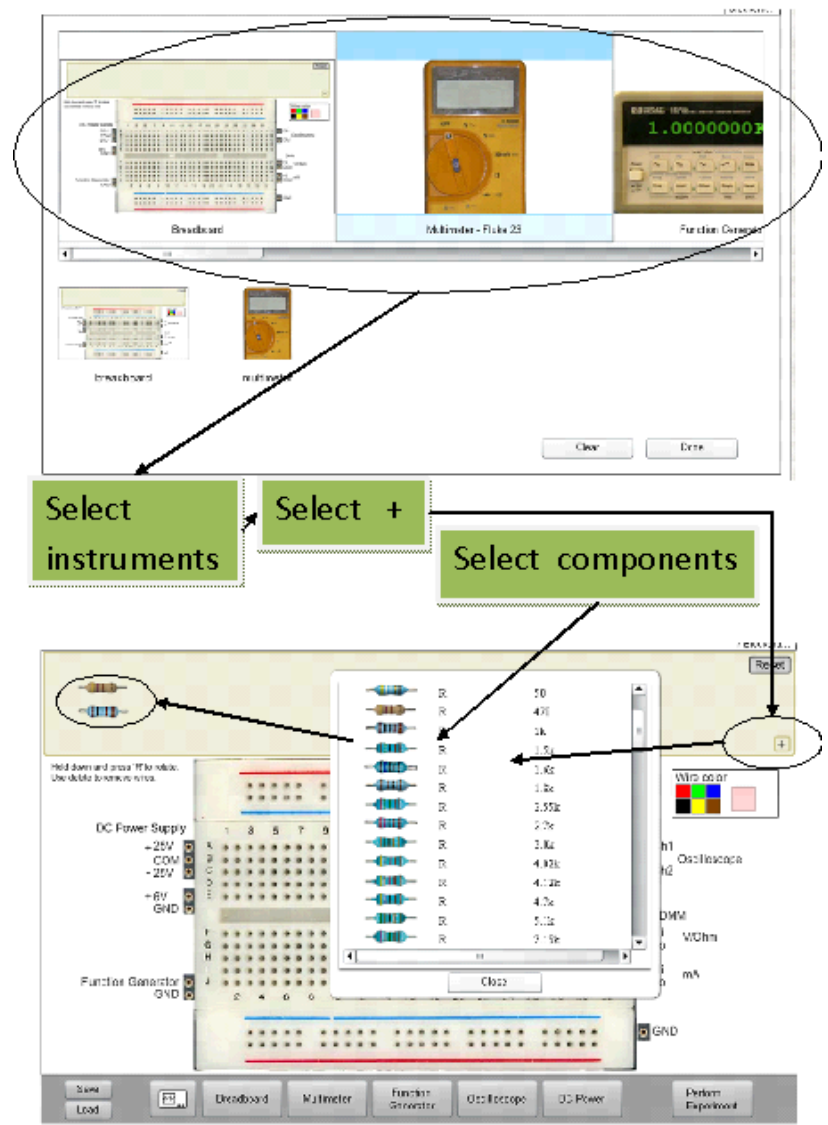

Figure 4. Top; the virtual instrument shelf and bottom; the component list.

defines more components than are available in the online component store. The Component Library is a part of the VISIR open source distribution. You can display the component library by pressing the plus $(+)$ sign in the lower right corner of the box for components in fig. 4. By clicking on a component in the component library, it will appear in the component box. If you cannot find a particular component, ask the administrator to include it. Add all the components given in the list of materials of your laboratory instruction manual. Close the component library by pressing the close button. After the setup is complete, press the save button to save your setup. Then, return to the webpage displayed lower in fig. 3. Choose a name of your prepared experiment and pick the file you have just saved. Finally, press the "Add" button to upload and add the prepared experiment to the system.

You must verify that all the circuits to be wired by the students in your session are permitted to be created. Ask the laboratory staff for a list of the current virtual instructor rules i.e. the Max Lists. Most likely, at least some of your circuits will not be supported and a number of your components may not be present in the online component store. Ask the staff to include them. Now you must define new Max Lists in collaboration with the staff. These lists should not only support your experiments but also support all safe circuits possible to create using components of the online component store extended with your components.

Examples of teaching \& learning materials produced by a teacher are; an instruction manual for the students that provides them with information on how to get access to

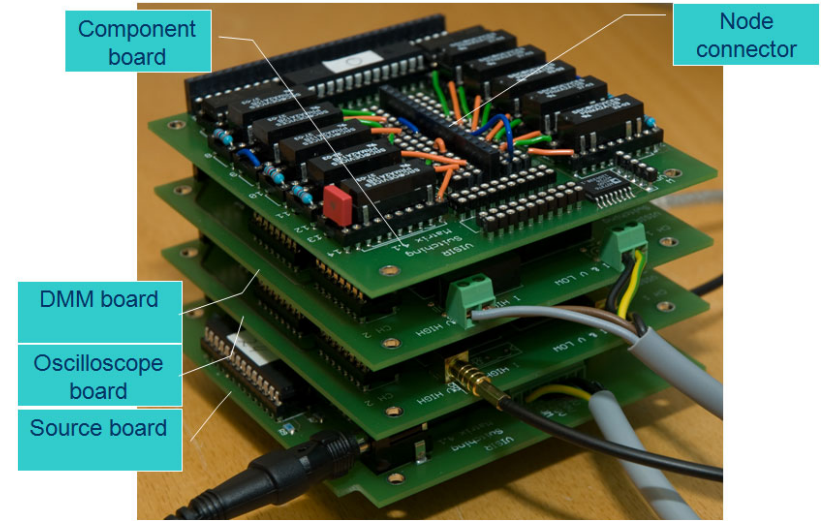

Figure 5. The switching matrix in VISIR [13].

VISIR laboratory and how to use the RL for experimental work [15]. For the laboratory sessions the teacher writes lab instruction manuals, describing the experiments to be performed during the sessions [16-18]. All the teaching \& learning materials will be stored in itslearning, the lab instruction manual as an assignment for the students. An assignment in itslearning indicates for the student that it is requested to submit a lab report.

Another option with the RL for a teacher is to integrate experimental work in a theory lecture by login on to the website VISIR laboratory and carry out remote experimental work in real time during the lecture. Thus, the theory for electronic circuits may be confirmed with experiments from the RL in theoretical lecture. The teacher may also have exams with exercises of experimental work using VISIR laboratory.

\section{EXAMPLES OF LABORATORY WORK}

In a study carried out during the period 2009-2011 two teachers and 94 students at Katedralskolan were participating in a project where Katedralskolan and BTH collaborate. They were divided into five groups, group A to group $\mathrm{E}$, regarding physics course and teacher (see Table 1).

Fig. 1 shows a typical practical session in VISIR. It has four steps; configure the circuit, configure the instrument (DMM), run the experiment, and analyze the results.

TABLE I.

STUDENT GROUPS A-E.

\begin{tabular}{|l|l|l|l|l|l|}
\hline Group & A & B & C & D & E \\
\hline Number of students & 18 & 20 & 18 & 20 & 18 \\
\hline Teacher & 1 & 1 & 1 & 2 & 1 \\
\hline Physics course & A & A & B & B & B \\
\hline $\begin{array}{l}\text { Performed } \\
\text { experiment }\end{array}$ & Lab1 & Lab1 & Lab2 & Lab2 & Lab3 \\
\hline Time & $\begin{array}{l}\text { May } \\
\text { 2009 }\end{array}$ & $\begin{array}{l}\text { Dec } \\
2010\end{array}$ & $\begin{array}{l}\text { May } \\
2009\end{array}$ & $\begin{array}{l}\text { Jan } \\
2011\end{array}$ & $\begin{array}{l}\text { May } \\
2011\end{array}$ \\
\hline
\end{tabular}

Lab1 deals with direct current [16]. The assignments were:

- Investigate the relationship between voltage and electric current, the Ohm's Law, for a component (resistor or conductor) that behaves according to Ohm's law over some operating range. A result from a student's lab report is shown in fig. 6 . 
- Investigate if the current was the same before a component as after in a circuit with two resistors in series.

- Check Kirchhoff's voltage and current law.

The students can only use $1 \mathrm{~K}, 2,7 \mathrm{~K}$ and $10 \mathrm{~K}$ resistors in different positions. All the experimental assignments have been prepared in advance with theory lessons for students and real experimental work. Before the students started to use the VISIR laboratory it was introduced by the teacher of the class, starting with a small presentation of the VISIR laboratory interface and a explanation on how to use the RL. Further, help for the Student is provided by manuals on itslearning [15]. Most of the students manage to carry out the laboratory assignment in school during two lab-session in physics the rest completed the assignment at home. Between two and fourteen accesses per student, in the course Katte on VISIR indicates the students' usage of the VISIR laboratory during their spare time. It was compulsory for each student to write a lab report, where they had to include theoretical calculations, VISIR laboratory measurements and screen dumps of the circuits.

In lab 2 the students performed labs on the RL with alternating current [17]. The tasks were about:

- Compare the impedance of the components in DCcircuits with AC-circuits.

- Investigate the components impedance at different frequencies for capacitors and coils.

- Relative phases between various voltages for the components, assessed on the remote oscilloscope.

The available components were; $1 \mathrm{~K}, 2,7 \mathrm{~K}, 10 \mathrm{~K}$ resistors, 82 millihenry coil and 56 nanofarad capacitor in different positions.

Lab 3 Group E, the same students as in Group A, but now third year students that have exams with exercises of experimental work using the VISIR laboratory. Lab3 was an exam with experimental assignments on the RL, based on the tasks in Lab2 [18]. They were not required to explanation how to use the RL in the exam. Within 75 minutes they had to do the experimental assignments. Every student downloaded a lab instruction guide from itslearning describing the three experimental assignments in the exam, one assignment for a DC circuit and two assignments for an AC circuit. They had to document the measurements from VISIR laboratory and a screen dump of the circuits into the lab instruction guide and then upload it to itslearning.

\section{EVALUATION}

After the sessions a questionnaire was passed to the students to acquire their opinion about the VISIR lab. The questionnaire has 13 items and covers four characteristics of a RL; 1) usability (Q2-Q4), 2) sense of reality (Q5-Q7), 3) usefulness (Q1, Q8-Q10) and 4) quality of the service (Q11). Q12 and Q13 are open ended question. The questions in questionnaire are presented in Table 2. For each item in the questionnaire a mark was calculated as the arithmetic mean of the marks given by the students for that particular item, see Table 2. The majority of the students were satisfied with VISIR. The students showed a great interest in the laboratory experiments, and appreciated that it was not simulations but happened in real life.

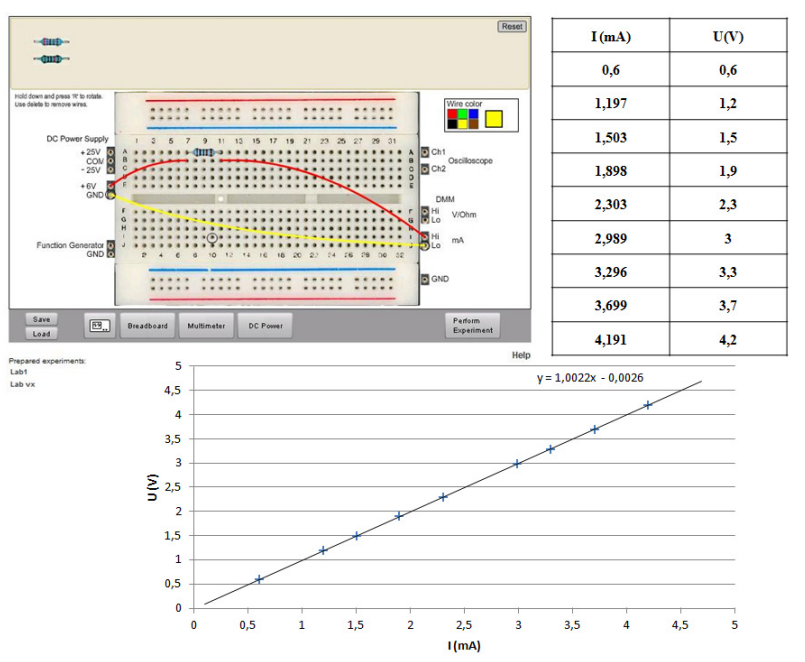

Figure 6. Result produced by a student performing Lab1, assigment1 in the Physics A course.

Based on the results of the questionnaire in Table II some conclusions can be remarked:

- VISIR is accepted by the students as a good learning tool. Usefulness and usability get high marks considering not all students at this age have developed an interest on electrical and electronic circuits.

- The opinion of the students of the group B is more positive as compared to the opinion of the students of group A. The VISIR-laboratory is the same, but during 2010 a special effort was made for creating a better manual and materials in order to provide a better explanation of VISIR: architecture, design, researchers, etc. If the students know the tool they will "trust" it. The fact that teacher1 had more experience of teaching with the RL is also likely be an argument for the more positive result in group B. Also, Katedralskolan supplied all the students in group B with a personal laptop computer during their time of study.

- The opinion of the students of the group D is more negative as compared to the other groups. The teacher of this group had a fairly limit experience of the RL. The fact that the students only used the RL ones, are maybe another explanation of the low marks. The fact that they used the RL in January and did the questionnaire in May the same year was probably not good either.

- Q11 got low marks from three groups. Group B probably because the VISIR was upgraded with new software during their usage of VISIR in December 2010. Some students had problem with remembering their password.

The open ended questions answers from students were;

Q12: Remote access to the laboratory enable you to perform physical experiments with similar instrument and components at home as in school. It feels trendy using the online remote laboratory and safe to know that you cannot destroy any equipment. It is easy to use, feels like working in reality and you wire a circuit very quickly. The framework and the concept. Available. The devices front panels are similar to the devices front panels of school. Funny. New idea. It is pleasant to wire the circuits. You can perform experimental work at home. It is real experimen- 
SPECIAL FOCUS PAPER

USING AN ONLINE REMOTE LABORATORY FOR ELECTRICAL EXPERIMENTS IN UPPER SECONDARY EDUCATION.

TABLE II.

RESULTS OF THE QUESTIONNAIRE FOR VISIR-BTH IN 2009-2011

\begin{tabular}{|c|c|c|c|c|c|c|c|}
\hline & & $\begin{array}{l}\text { Results of the Questionnaire for usage of OpenLabs } \\
\text { Scale: } 1 \text { (I not agree) - } 5 \text { (I agree) }\end{array}$ & Group A & Group B & Group C & Group D & Group E \\
\hline & & Surveys/Number of students in the course & $15 / 18$ & $16 / 20$ & $14 / 15$ & $19 / 20$ & $14 / 18$ \\
\hline \multirow{3}{*}{ 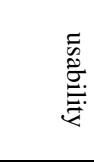 } & Q2 & The remote laboratory helps me with my hands-on laboratory work. & 3,0 & 4,3 & 3,4 & 2,4 & 3,9 \\
\hline & Q3 & $\begin{array}{l}\text { I have been motivated by the Remote laboratory to learn more about } \\
\text { the subject. }\end{array}$ & 2,6 & 3,4 & 2,7 & 2,1 & 2,8 \\
\hline & Q4 & It is a good idea to extend this remote laboratory to all the students. & 4,2 & 4,0 & 4,0 & 2,4 & 3,6 \\
\hline \multirow{3}{*}{ 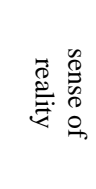 } & Q5 & Using the remote laboratory, I feel it is real and not a simulation. & 2,8 & 3,6 & 3,1 & 2,3 & 3,2 \\
\hline & Q6 & $\begin{array}{l}\text { I would like to have a webcam to see something at the remote } \\
\text { laboratory. }\end{array}$ & 3,2 & 3,1 & 2,7 & 1,8 & 3,1 \\
\hline & Q7 & $\begin{array}{l}\text { Being far from the remote laboratory, I have felt myself to be in } \\
\text { control of it. }\end{array}$ & 3,0 & 4,0 & 2,9 & 2,9 & 2,9 \\
\hline \multirow{4}{*}{ 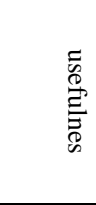 } & Q1 & I have enjoyed using the remote laboratory. & 3,0 & 3,8 & 3,0 & 2,1 & 3,2 \\
\hline & Q8 & The remote laboratory is easy to use the first time. & 3,0 & 3,0 & 2,6 & 2,1 & 3,1 \\
\hline & Q9 & The different devices are easy to use. & 3,6 & 3,9 & 4,6 & 2,7 & 3,4 \\
\hline & Q10 & $\begin{array}{l}\text { The devices front panels at the remote laboratory are similar to our } \\
\text { schools real devices. }\end{array}$ & 3,8 & 3,8 & 3,4 & 2,8 & 3,5 \\
\hline \multirow{3}{*}{ 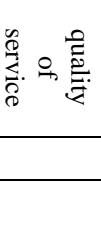 } & Q11 & Always when I logged in to the remote laboratory I got access to it. & 3,6 & 1,8 & 3,7 & 1,8 & 1,6 \\
\hline & Q12 & State two things you think are positive with the remote laboratory. & & & & & \\
\hline & Q13 & $\begin{array}{l}\text { Suggest two things that would help your teacher to improve the } \\
\text { remote laboratory. }\end{array}$ & & & & & \\
\hline
\end{tabular}

tal work, which is more motivating and makes the assignment funnier. Instructive. Innovative. Easily accessible. You do not have to take out components and instruments.

Q13: A guide available when you have trouble with the wired circuit. Make it possible for several students to perform experiments together, collaborative working. Increase the feeling of reality with a webcam. Instruction manual for the breadboard. A help-square where you can read about the science-theory. Make it possible to see all the devices front panels at the same time. Use it more frequently. Make it more user-friendly. Make it look more real.

\section{CONCLUSION}

The implications from this project are that the remote laboratory is easy to implement for use by both by teachers and students. It is possible to integrate with the learning management system of the school. The way of carrying out experimental work provides the students with more time for experimental work as compared to what is offered by the school in the hands-on lab. The workbench for electrical experiments can be used by many students performing different experiments simultaneously. It is convenient to use the remote laboratory when you as a teacher do a demonstration for the students.

The students' satisfaction with the RL and perception of the RL resulted in a proposal of improvements in the RL's user interface. The majority of the students were satisfied. The students showed great interest in the labs, and appreciated that it was not simulations but real life experiments.

Future work in VISIR is to integrating another DMM that will provide more potential to assemble circuits. Enable the possibility to see all the devices front panels at the same time to enhance the RL. Make improvements in user interface to fit students at upper secondary schools better.

\section{REFERENCES}

[1] A. Azad, M. Auer and V. Harward (Eds.), Chapter 15 in Internet Accessible Remote Laboratories: Scalable E-Learning Tools for Engineering and Science Disciplines, IGI Global, USA, pp. 294317, ISBN10: 1613501862, doi:10.4018/978-1-61350-1863.ch015

[2] L. Gomes and J. Garcia-Zubia (eds), Chapter 11 in Advances on remote laboratories and e-learning experiences, University of Deusto, Bilbao, Spain, 2007, pp. 247-267, ISBN 978-84-9830077-2.

[3] I. Gustavsson et al., "A Flexible Electronics Laboratory with Local and Remote Workbenches in a Grid”, International Journal of Online Engineering, vol 4, no 2, pp. 12-16, 2008.

[4] I. Gustavsson et al., "On Objectives of Instructional Laboratories, Individual Assessment, and Use of Collaborative Remote Laboratories”, IEEE Trans. on Learning Tech., vol. 2, pp. 263-274, Oct.Dec. 2009. http://dx.doi.org/10.1109/TLT.2009.42

[5] J. Zackrisson, I. Gustavsson and L. Håkansson "An Overview of the VISIR Open Source Distribution 2007”, Proceedings of the REV 2007 Conference, Porto, Portugal, June 25-27, 2007.

[6] J. García Zubia et al.,"LXI technologies for remote labs: an extension of the VISIR project", International Journal of Online Engineering, vol 6, no S1, pp. 25-35, 2010.

[7] D.G. Zutin, "A VISIR Lab Server for the iLab Shared Architecture", International Journal of Online Engineering, vol 7, no S1, pp. 14-17, 2011.

[8] Gustavo, R. A. et al. "Using VISIR in a Large Undergraduate Course: Preliminary Assessment Results." International Journal of Engineering Pedagogy, vol 1, no 1, pp 12-19, 2011.

[9] L. D. Feisel, and A. J. Rosa, "The role of the laboratory in undergraduate engineering education”. J.Eng. Education, pp. 121-130, 2005.

[10] Z. Nedic, and J. Machotka. "Remote Laboratory NetLab for Effective Teaching of 1st Year Engineering Students." International Journal of Online Engineering vol 3, no.3, 2007.

[11] J. Ma, \& J. V. Nickerson, "Hands-on, simulated, and remote laboratories: A comparative literature review", ACM Computing 
Surveys, vol. 38, no. 3, pp. 7, 2006. http://dx.doi.org/10.1145/ 1132960.1132961

[12] Katedralskolan, http://www.lund.se/Gymnasieskolor/Katedralskol an/In-English/ accessed Jan. 20, 2012.

[13] I. Gustavsson, “Teacher's guide to the VISIR online laboratory for electrical experiments", http://openlabs.bth.se/electronics/index. php?page=AboutPage\#, accessed Jan. 14, 2012.

[14] I. Gustavsson et al., “A Telemanipulator for Remote Wiring of Electrical Circuits”, Proceedings of REV 2008, Duesseldorf, Germany, June 2008

[15] L. Claesson, “Manual”, http://www.katte.se/fysik/openLab.htm, accessed Jan. 14, 2012.

[16] L. Claesson, “lab1”, http://www.katte.se/fysik/openLab.htm, accessed Jan. 14, 2012.

[17] L. Claesson, “lab2”, http://www.katte.se/fysik/openLab.htm, accessed Jan. 14, 2012.
[18] L. Claesson, "lab3”, http://www.katte.se/fysik/openLab.htm, accessed Jan. 14, 2012.

\section{AUTHORS}

L. Claesson is with Blekinge Institute of Tecnology, Karlskrona, Sweden (e-mail: lena.claesson@ bth.se).

L. Håkansson is with Blekinge Institute of Tecnology, Karlskrona, Sweden (e-mail: lars.håkansson@ bth.se).

This work was supported by Calouste Gulbenkian Foundation, Lisbon, Portugal. It is an extended version of a presentation given during the 1st Experiment@ International Conference, 17/18 November 2011 in Lisbon, Portugal. Manuscript received 21 January 2012. Published as resubmitted by the authors 18 March 2012. 